\title{
Effect of bevacizumab on expression level of GLI1 and ING4 in colon cancer animal model
}

\author{
BING SUO $^{1 *}$, CAIYU WU $^{1 *}$ and FEN MEI $^{2}$ \\ ${ }^{1}$ General Hospital of Heilongjiang Province Land Reclamation Bureau, Harbin, Heilongjiang 150088; \\ ${ }^{2}$ Department of Medical Laboratory, The Central Hospital of Wuhan, Tongji Medical College, \\ Huazhong University of Science and Technology, Wuhan, Hubei 430014, P.R. China
}

Received October 18, 2019; Accepted October 31, 2019

DOI: $10.3892 /$ ol.2020.11677

\begin{abstract}
This study aimed to investigate the effect of bevacizumab on GLI1 and ING4 expression in colon cancer animal model. Colon cancer model in rats was induced by azoxymethane (AOM). Bevacizumab was used for the treatment of colon cancer rats. Tumor volume and weight were measured, tumor growth curve was visualized and tumor inhibition rate was calculated. GLI1 and ING4 of colon cancer cells were silencing expressed. Western blot analysis was used to detect the expressions of GLI1, ING4, caspase-3, Bax, $\beta$-catenin, Bcl2, PTEN, PI3K, Akt, NF- $\mathrm{B}$. The apoptosis rate was detected by flow cytometry. MTT assay was used to detect cell activity to get $\mathrm{IC}_{50}$ value. After $\mathrm{AOM}$ induced colon cancer model in rats, the expressions of ING4, caspase-3, Bax and PTEN were downregulated, the expressions of GLI1, $\beta$-catenin, Bcl2, PI3K, Akt and $\mathrm{NF}-\kappa \mathrm{B}$ were upregulated and the apoptosis rate was downregulated. After bevacizumab treatment, the tumor volume and weight decreased, the expressions of ING4, caspase-3, Bax, PTEN were upregulated, the expressions of GLI1, $\beta$-catenin, $\mathrm{Bcl} 2, \mathrm{PI} 3 \mathrm{~K}, \mathrm{Akt}, \mathrm{NF}-\kappa \mathrm{B}$ were downregulated, and the cell apoptosis rate increased. Cell experiments showed that GLI1 promotes tumor growth and reduces the sensitivity of bevacizumab, while ING4 inhibits tumor growth and increases the sensitivity of bevacizumab. Bevacizumab inhibits the growth of colon cancer tumor by upregulating ING4 and downregulating GLI1.
\end{abstract}

\section{Introduction}

Colon cancer is the third most common cancer in the world with a very high mortality rate (1). In China, the incidence of

Correspondence to: Dr Fen Mei, Department of Medical Laboratory, The Central Hospital of Wuhan, Tongji Medical College, Huazhong University of Science and Technology, 26 Shengli Street, Wuhan, Hubei 430014, P.R. China

E-mail: f9r9m5@163.com

*Contributed equally

Key words: colon cancer, GLI1, ING4, bevacizumab colon cancer increased with an average rate of $2.34 \%$ per year between 1990 and 2016 (2). Age, diabetes, gene mutation, abnormal expression of non-coding RNA and gastroenteric bowel disease are all possible high-risk factors for colon cancer (3-7). The pathogenesis of colon cancer involves activation of multiple signal pathways. In colon cancer, mitochondrial retrograde pathway mediated by TFAM promotes tumor occurrence by inhibiting Wnt/ $\beta$-catenin pathway (8). The intestinal insulin /IGF-1 pathway promotes the formation of colon cancer tumors by promoting the expression of FoxO1 (9).

Inhibitor of growth 4 (ING4) belongs to the growth inhibitory factor family and is a type II tumor suppressor gene (10). Ma et al (11) found that the inhibitory effect of ING4 on melanoma can be realized by activating Fas/caspase- 8 apoptosis pathway. Qian et al (12) believed that ING4 can inhibit the growth and metastasis of liver cancer tumor by inhibiting NF- $\mathrm{KB}$ and upregulating FoxO3. ING4 plays an important role in colon cancer. In colon cancer, ING4 inhibits cell proliferation and reverses epithelial-mesenchymal transition by regulating the expression of target proteins such as p-Stat3, Ki-67, p21 and E-cadherin (13-15).

GLI1 protein belongs to the zinc finger protein Kruppel family, and GLI1 is closely related to cancer. GLI1 can inhibit the expression of E-adherin protein in breast cancer cells after being activated by SHH protein, and eventually weaken the ability of cell migration and invasion (16). The high expression of GLI1 in glioma cells can promote the proliferation and activity of glioma cells and reduce the sensitivity of cells to vincristine (17). In colon cancer, GLI1 is activated by PI3K/Akt/NF- $\mathrm{KB}$ pathway and can regulate cell biological processes such as epithelial-mesenchymal transition and cell cycle (18). In addition, the co-expression of GLI1 and p-S6K protein is closely related to lymph node metastasis and TNM staging (19).

Bevacizumab is a common anticancer drug. In order to understand the effect of bevacizumab on colon cancer and its relationship with GLI1 and ING4, the rat colon cancer model was induced by azoxymethane (AOM) and treated with bevacizumab.

\section{Materials and methods}

AOM-induced colon cancer model in rats. SD male rats were randomly divided into control group, sham operation group, 
negative control group (NC group), model group, low-dose bevacizumab group and high-dose bevacizumab group with 10 rats in each group. Except control group and sham operation group, rats in other groups received intraperitoneal injection of AOM $(1 \mathrm{ml}, 15 \mathrm{mg} / \mathrm{kg}$, dissolved in PBS buffer) once every 2 weeks. The rats in the control group did not receive any treatment, while the rats in the sham-operation group received intraperitoneal injection of $1 \mathrm{ml}$ of PBS buffer once every 2 weeks. After modeling, the low-dose bevacizumab group was treated with $25 \mathrm{~g} / 1$ of bevacizumab (dissolved in $0.9 \% \mathrm{NaCl}$ solution), the high-dose group was treated with $100 \mathrm{~g} / \mathrm{l}$ bevacizumab (dissolved in $0.9 \% \mathrm{NaCl}$ solution), and the $\mathrm{NC}$ group was treated with $0.9 \% \mathrm{NaCl}$ solution injection. The length and width of the tumor were measured and recorded every 1 week starting from 0 weeks after modeling, and the tumor was weighed 3 weeks after modeling to record the tumor quality. Tumor volume $=$ tumor length, tumor width 2 , tumor inhibition rate $=100 \%$ ( 1 - tumor mass in bevacizumab treatment group/tumor mass in negative control group).

The study was approved by the Ethics Committee of General Hospital of Heilongjiang Province Land Reclamation Bureau (Harbin, China).

Cell culture and transfection. Colon cancer cells SW480 and SW620 were purchased from the Cell Bank of the Typical Culture Preservation Committee of the Chinese Academy of Sciences (Shanghai). The above cells were were cultured in animal cell incubator at $37^{\circ} \mathrm{C}$ with $5 \% \mathrm{CO}_{2}$ before transfection. The culture medium system was RPMI-1640 medium $+10 \%$ fetal bovine serum solution $+1 \%$ penicillin/streptomycin solution. Subsequent experiments would be carried out after cell culture to logarithmic growth phase.

The day before transfection, the culture medium was replaced with fetal bovine serum-free culture medium. On the day of transfection, cells were inoculated into 6-well plates with $1 \times 10^{5}$ cells/well. GLI1, siRNA, ING4 siRNA and NC were all purchased from Shanghai Sangon Biotech. Cell lines were transfected with Lipofectamine 2000 transfection kit (Invitrogen; Thermo Fisher Scientific, Inc.). The procedures referred to the kit instructions. After $8 \mathrm{~h}$ of transfection, fresh culture was replaced. Then cells were cultured in animal cell incubator at $37^{\circ} \mathrm{C}$ with $5 \% \mathrm{CO}_{2}$. Subsequent experiments can be carried out after $48 \mathrm{~h}$ of continuous culture.

Flow cytometer. The sample to be tested was prepared into cell suspension. The number of cells was controlled to $1 \times 10^{6}$. Cells were immobilized in $70 \%$ ethanol ice-cold solution for $30 \mathrm{~min}$ at $4^{\circ} \mathrm{C}$. The ethanol solution was then removed and the cell particles were incubated in Annexin V-FITC/7-AAD mixed solution. FACScan flow cytometer (BD Biosciences) was used to analyze the apoptosis.

MTT assay. Transfected cells with good growth status were enzymatically hydrolyzed for $2 \mathrm{~min}$, then the enzyme solution was sucked and fresh culture medium was added to prepare cell suspension. Four 96-well plates were taken and cells were inoculated into the well plates according to the specification of $5 \times 10^{3}$ cells $/ 100 \mu \mathrm{l} /$ well, with 3 wells in each group. One well plate was taken out every $24 \mathrm{~h}, 5 \mathrm{mg} / \mathrm{ml}$ MTT solution was added $10 \mu \mathrm{l} /$ well, the cells were continued to culture for $1 \mathrm{~h}$,

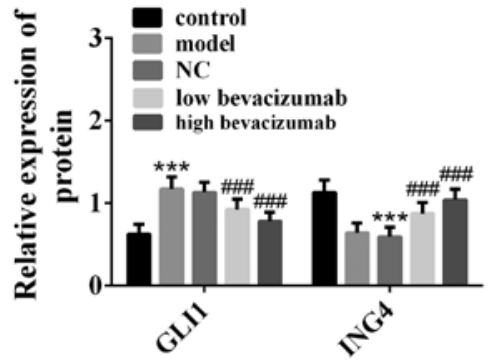

Figure 1. Bevacizumab inhibits GLI1 and promotes ING4. ${ }^{* * *} \mathrm{P}<0.01 \mathrm{com}-$ pared with the control group; ${ }^{\# \#} \mathrm{P}<0.01$ compared with model group.

then the culture medium was sucked, and the OD value was measured at $570 \mathrm{~nm}$ with an enzyme reader. The experiment was repeated 3 times to visualize the cell activity-time curve.

Colon cancer cells were inoculated into 96-well plates with $8 \times 10^{3}$ cells per well, cultured in animal cell incubator at $37^{\circ} \mathrm{C}$ with $5 \% \mathrm{CO}_{2}$ for $12 \mathrm{~h}$, then added with bevacizumab (1-1,000 g/l, with the increase of concentration gradient rises) for further culture. After $48 \mathrm{~h}, 101 \mathrm{MTT}$ was added to each well for $1 \mathrm{~h}$ in dark room. After that, the culture medium was sucked. The OD value at $570 \mathrm{~nm}$ was measured by an enzyme-labeled instrument, and the cell activity-concentration curve was drawn. SPSS analysis curve was used to determine the $\mathrm{IC}_{50}$ value of the semi-inhibitory concentration. The experiment was repeated 3 times.

Western blot analysis. Part of rat colon cancer tissue was taken and cut to pieces, and tissue samples were treated with cell protein extract (cell lysate: protease inhibitor: phosphatase inhibitor $=98: 1: 1)$, the extractive solution was centrifuged at $1.6 \times 10^{4} \mathrm{x} \mathrm{g}$ at $4^{\circ} \mathrm{C}$ for $15 \mathrm{~min}$, and the supernatant was collected. The supernatant was subjected to SDS-PAGE electrophoresis to distinguish proteins. The proteins were transferred to $\mathrm{NC}$ membrane and placed for $1 \mathrm{~h}$ at room temperature (the blocking solution was 5\% skim milk-PBS solution). GLI1, ING4, caspase-3, Bax, $\beta$-catenin, Bcl2, PTEN, PI3K, Akt, NF-kB primary antibodies were then added and placed overnight at $4^{\circ} \mathrm{C}$. PBS solution was used for washing, the operation was repeated three times, goat anti-rabbit secondary antibody (HRP crosslinking) was added, and the mixture was placed for $1 \mathrm{~h}$ at room temperature. Finally, the membrane was washed with PBS solution and visualized using enhanced chemiluminescence method. The internal reference protein was $\beta$-actin, and the relative expression level of the protein to be detected $=$ gray value of the band to be detected/gray value of the $\beta$-actin band. GLI1, ING4, caspase-3, Bax, $\beta$-catenin, Bc12, PTEN, PI3K, Akt, NF- $\kappa \mathrm{B}, \beta$-actin and goat anti-rabbit antibody were all purchased from Shanghai Abcam Company.

Statisticsal analysis. The above index data were input into SPSS 20.0 software package (Asia Analytics Formerly SPSS China), and GraphPad Prism 6.0 was used for statistical analysis. Each experiment was repeated 3 times. The measurement data were expressed by mean $\pm \mathrm{SD}$. Independent sample t-test was used for the data comparison method between the two groups. One-way ANOVA was used for the comparison among multi-groups, LSD-t test for pairwise comparison 
A

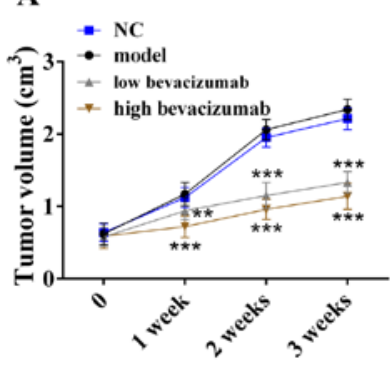

B

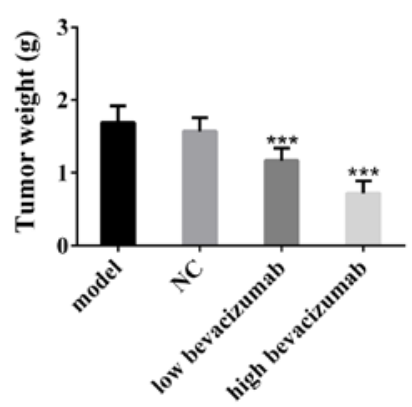

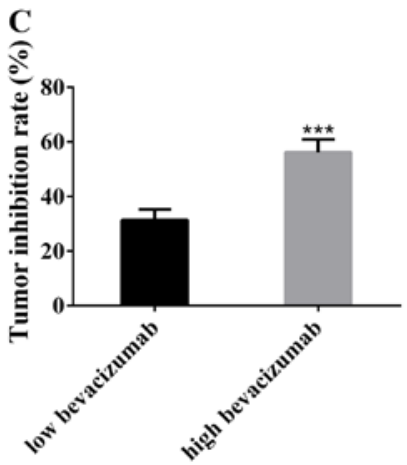

Figure 2. Bevacizumab effectively inhibits tumor growth. (A) Inhibitory effect of bevacizumab on tumor volume; ${ }^{* *} \mathrm{P}<0.01,{ }^{* * *} \mathrm{P}<0.001$, compared with control group, (B) Inhibitory effect of bevacizumab on tumor weight; ${ }^{* * *} \mathrm{P}<0.001$, compared with model group. (C) The therapeutic effect of bevacizumab may be dose-dependent; ${ }^{* * *} \mathrm{P}<0.001$, compared with low bevacizumab.
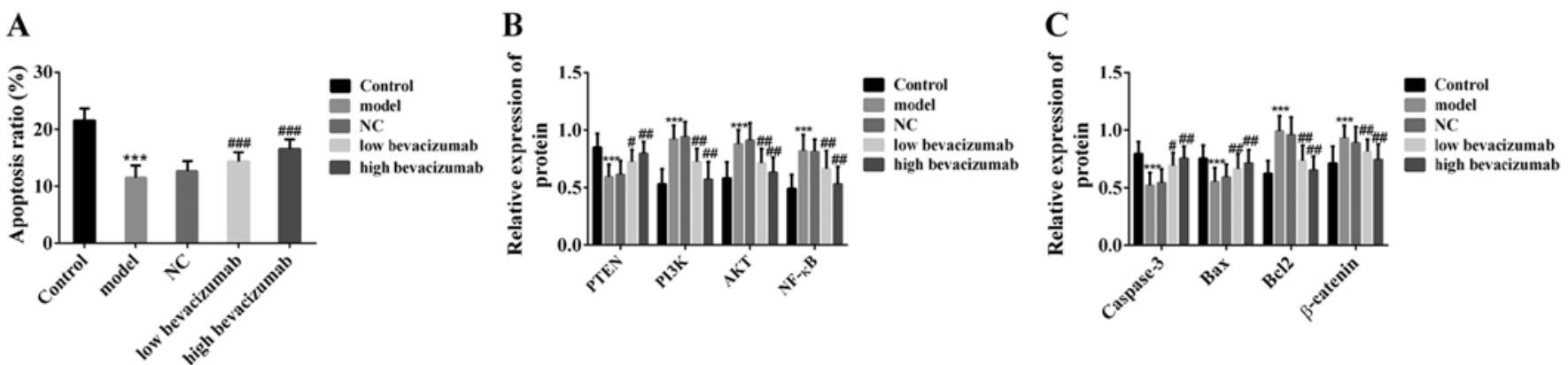

Figure 3. Bevacizumab promotes cell apoptosis by promoting caspase-3, Bax, PTEN and inhibiting $\beta$-catenin, Bcl2, PI3K, Akt, NF-kB. (A) Bevacizumab promotes cell apoptosis; ${ }^{* * *} \mathrm{P}<0.001$, compared with control group, and ${ }^{\# \# \#} \mathrm{P}<0.001$, compared with model group. (B) Bevacizumab upregulates $\mathrm{PTEN}$ and downregulates PI3K, Akt, NF-NF- $\mathrm{KB}$; ${ }^{* * *} \mathrm{P}<0.001$, compared with control group, ${ }^{\#} \mathrm{P}<0.05$ and ${ }^{\# \#} \mathrm{P}<0.01$, compared with model group. (C) Bevacizumab upregulates caspase- 3 and Bax and inhibits Bcl 2 and $\beta$-catenin; ${ }^{* * *} \mathrm{P}<0.001$, compared with model group, and ${ }^{\#} \mathrm{P}<0.05$ and ${ }^{\# \#} \mathrm{P}<0.01$, compared with model group.

afterwards. All data were tested by two-tailed test. The value of $95 \%$ was taken as confidence interval, the difference was statistically significant when $\mathrm{P}<0.05$.

\section{Results}

Bevacizumab inhibits GLII and promotes ING4. In this study, AOM was used to induce colon cancer model in rats, and bevacizumab was given to colon cancer model rats. The expression of GLI1 and ING4 in rat colon cancer tissues was detected by western blot analysis, and the results are shown in Fig. 1. Compared with the control group, GLI1 expression was upregulated and ING4 expression was downregulated in the model group. Compared with the model group, GLI1 expression was downregulated in low-dose bevacizumab group and high-dose bevacizumab group, while ING4 expression was upregulated. In addition, the change degree of GLI1 and ING4 in low-dose bevacizumab group was less than those in high-dose bevacizumab group. The above results indicated that bevacizumab can inhibit GLI1 and promote ING4 for colon cancer treatment.

Bevacizumab effectively inhibits tumor growth. In order to verify the inhibitory effect of bevacizumab on colon cancer tumors, the tumor weight and volume were measured and the tumor inhibitory rate was calculated. The results are shown in Fig. 2. Compared with the model group, the tumor volume in the bevacizumab treatment group decreased and increased slowly with the time. The tumor weight of bevacizumab treatment group was also statistically smaller than that of the model group. In addition, the tumor inhibition rate of low-dose bevacizumab group was lower than that of high-dose bevacizumab group. The above results indicated that bevacizumab can inhibit tumor growth, and its inhibitory effect may be dose-dependent.

Bevacizumab promotes apoptosis by promoting caspase-3, Bax, PTEN and inhibiting $\beta$-catenin, Bcl2, PI3K, Akt, $N F-\kappa B$. In order to understand the molecular mechanism of bevacizumab in the treatment of colon cancer, the apoptosis was detected by flow cytometry and the expression of related proteins was detected by western blot analysis. Fig. 3A showed that compared with the control group, the apoptosis rate of the model group was reduced. Compared with the model group, the apoptosis rate of bevacizumab treatment group increased, and the apoptosis rate of low-dose group was lower than that of high-dose group. Fig. 3B and $\mathrm{C}$ showed that compared with the control group, the expression of PTEN, caspase-3 and $\mathrm{Bax}$ in the model group was downregulated, and the expression of $\mathrm{PI} 3 \mathrm{~K}, \mathrm{Akt}, \mathrm{NF}-\kappa \mathrm{B}, \beta$-catenin and $\mathrm{Bcl} 2$ were upregulated. Compared with the model group, the expression of PTEN, caspase-3 and Bax in bevacizumab treatment 
A

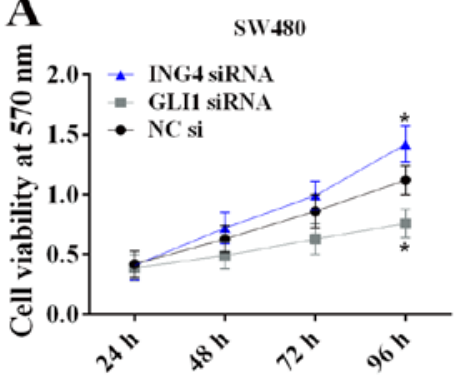

D

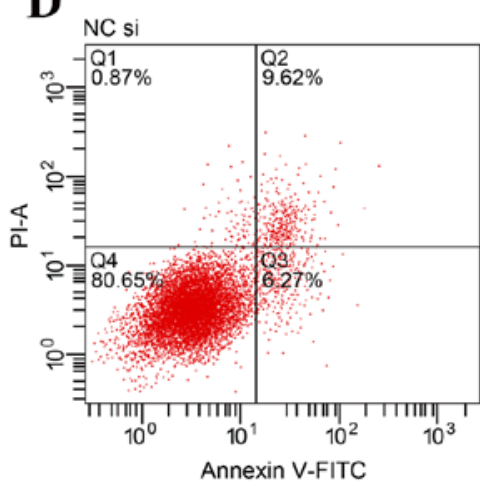

E

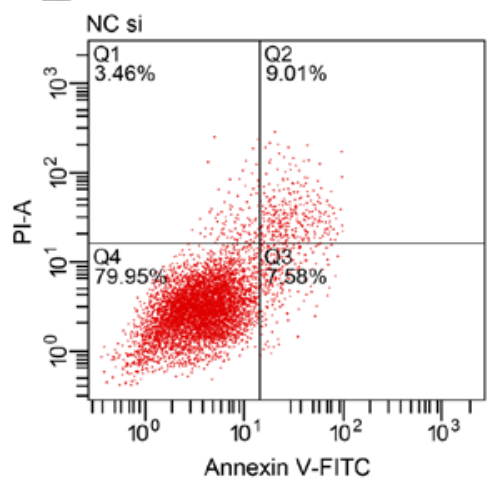

B
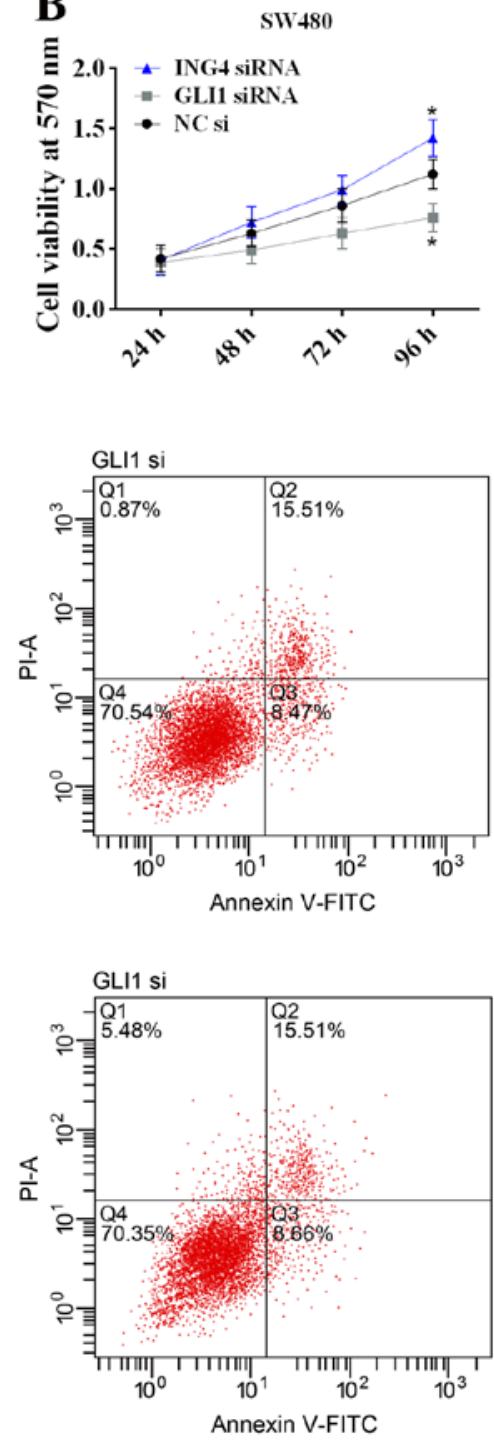

C
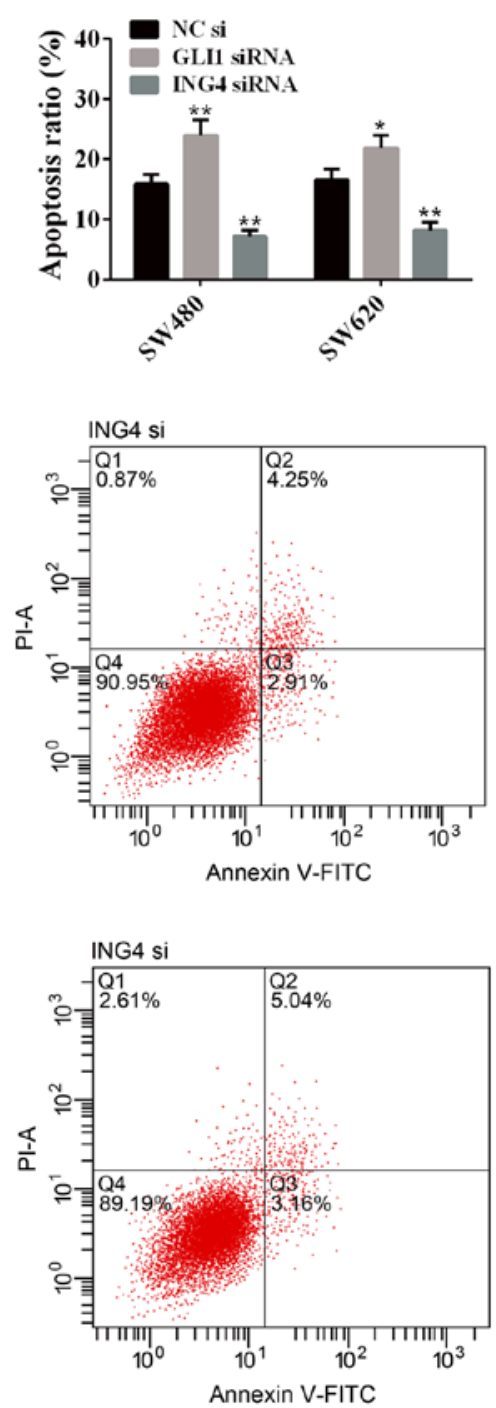

Figure 4 . GLI14 inhibits cell apoptosis and promotes cell proliferation, while ING4 inhibits cell proliferation and promotes cell apoptosis. (A) GLI1 increases the activity of SW480 cells, ING4 decreases the activity of SW480 cells. (B) GLI1 promotes SW620 cell activity, ING4 inhibits SW620 cell activity; (C) GLI1 promotes cell apoptosis, ING4 inhibits cell apoptosis. (D) flow cytometry was used to detect the effect of GLI1/ING4 on apoptosis of SW480 cells. (E) Flow cytometry was used to detect the effect of GLI1/ING4 on apoptosis of SW620 cells. ${ }^{*} \mathrm{P}<0.05,{ }^{* *} \mathrm{P}<0.01$ compared with NC group.

group was upregulated, while PI3K, Akt, NF- $\kappa \mathrm{B}, \beta$-catenin and $\mathrm{Bcl} 2$ were downregulated, and the change degree in high dose group was greater than that in low dose group. The above results showed that bevacizumab can promote cell apoptosis by promoting the expression of caspase-3, Bax and PTEN and inhibiting $\beta$-catenin, Bcl2, PI3K, Akt and NF- $\kappa$ B.

GLI1 inhibits apoptosis, while ING4 promotes apoptosis. In order to understand the effect of GLI1 and ING4 on colon cancer, siRNA was used to silence GLI1 and ING4 of colon cancer cells, MTT was used to detect cell activity, and flow cytometry was used to detect cell apoptosis. Fig. 4 showed that the deletion of GLI1 inhibits cell activity and promotes cell apoptosis. The deletion of ING4 increases cell activity and inhibits cell apoptosis. The above results showed that GLI14 inhibits cell apoptosis and promotes cell proliferation, while ING4 inhibits cell proliferation and promotes cell apoptosis.
Effect of GLII and ING4 on apoptosis protein and $P T E N / P I 3 K / A k t / N F-\kappa B$ pathway. Fig. $5 \mathrm{~A}$ and B showed that ING4 upregulates the expression levels of caspase-3 and Bax, and downregulates $\beta$-catenin and $\mathrm{Bcl} 2$. GLI1 upregulates $\beta$-catenin and $\mathrm{Bcl} 2$, and downregulates caspase-3 and Bax. Fig. 5C and D showed that ING4 promotes PTEN expression and inhibits PI3K, Akt, NF- $\mathrm{BB}$. GLI1 inhibits PTEN expression and promotes $\mathrm{PI} 3 \mathrm{~K}, \mathrm{Akt}$ and $\mathrm{NF}-\kappa \mathrm{B}$ expression.

GLII and ING4 affect the sensitivity of colon cancer cells to bevacizumab. In order to discuss the significance of GLI1 and ING4 in bevacizumab in the treatment of colon cancer, the $\mathrm{IC}_{50}$ value was collected by MTT method, and the effects of GLI1 and ING4 on the sensitivity of cell bevacizumab were discussed. The results of Fig. 6 showed that, compared with $\mathrm{NC}$ group, the deletion of GLI1 increases the $\mathrm{IC}_{50}$ value of cells with bevacizumab, while the deletion of ING4 decreases the $\mathrm{IC}_{50}$ value of cells with bevacizumab. The above results 
A
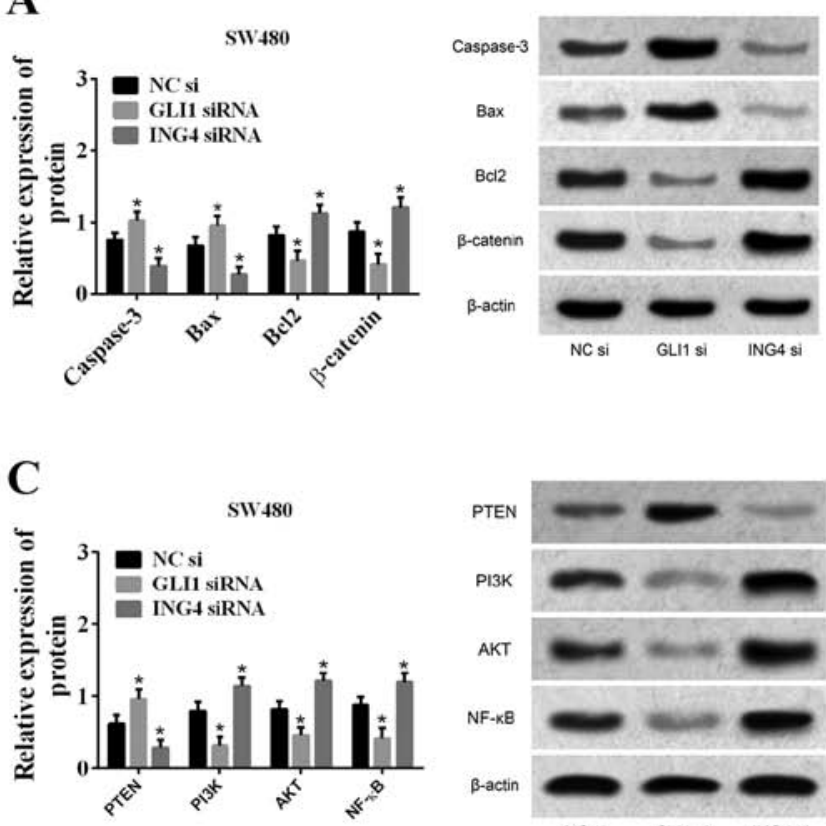

B

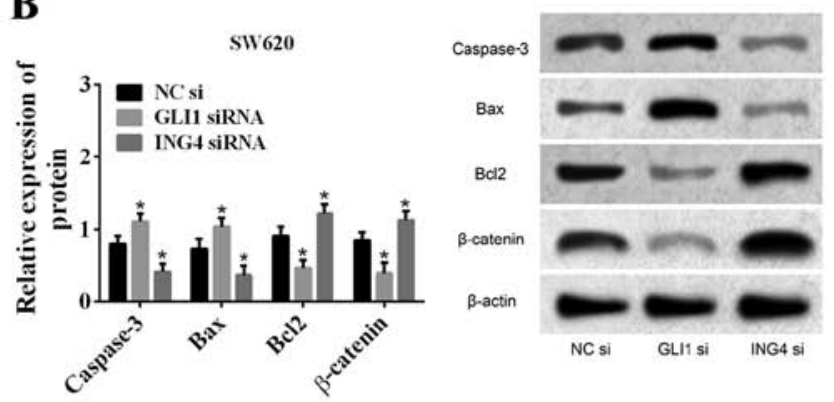

D

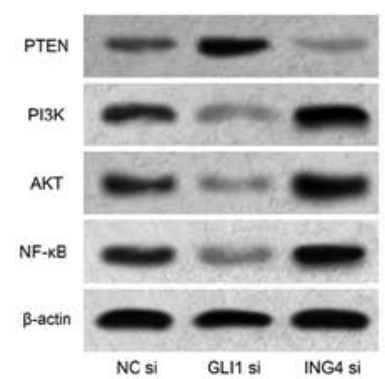

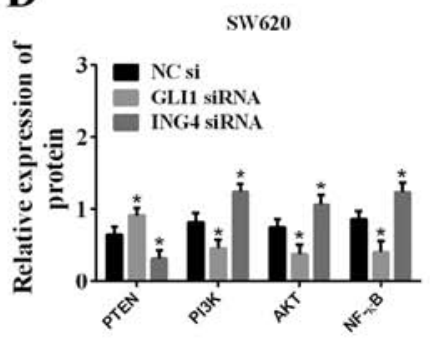

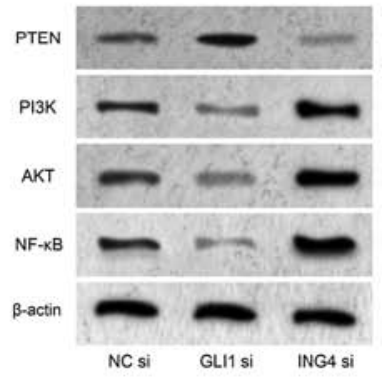

Figure 5. Effect of GLI1 and ING4 on protein. (A) Effects of GLI1 and ING4 on caspase-3, Bax, Bcl2 and $\beta$-catenin in SW480. (B) Effects of GLI1 and ING4 on caspase-3, Bax, Bcl2 and $\beta$-catenin in SW620. (C) Effects of GLI1 and ING4 on PTEN, PI3K, Akt and NF- $\mathrm{kB}$ in SW480. (D) Effects of GLI1 and ING4 on PTEN, PI3K, Akt and NF- $\kappa$ B in SW620; ${ }^{\mathrm{P}}<0.05$ compared with NC group.

A

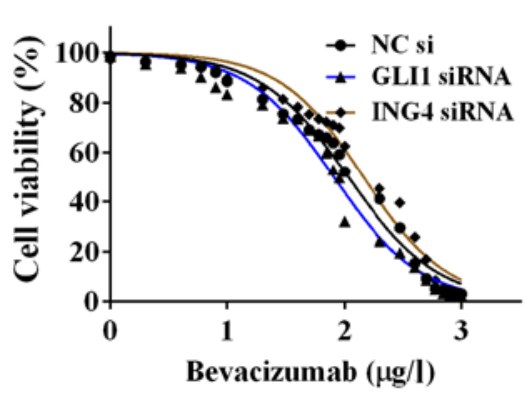

B

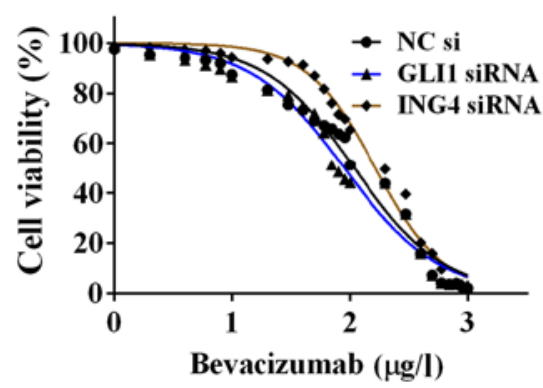

C

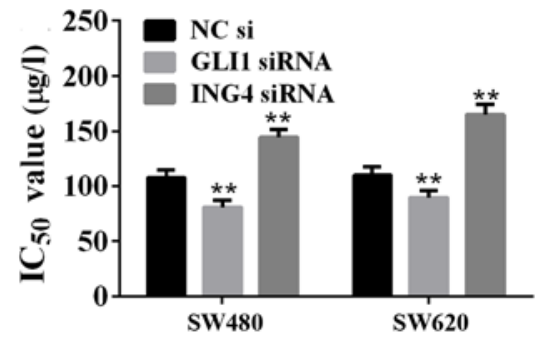

Figure 6. GLI1 and ING4 affect the sensitivity of colon cancer cells to bevacizumab. (A) Cell activity of SW480 cells treated with different doses of bevacizumab. (B) $\mathrm{IC}_{50}$ value of SW620 cell with bevacizumab. (C) $\mathrm{IC}_{50}$ value; ${ }^{* *} \mathrm{P}<0.01$ compared with NC group.

showed that GLI1 decreases the sensitivity of cells to bevacizumab, while ING4 increases the sensitivity of cells to bevacizumab.

\section{Discussion}

Bevacizumab is a humanized monoclonal antibody against vascular endothelial growth factor, which can inhibit tumor by inhibiting vascular endothelial growth factor (20). The results in this study verified that the tumor volume and weight are significantly reduced after treating with bevacizumab, and the curative effect of bevacizumab may be dose-dependent. The results showed that bevacizumab could upregulate ING4, promote cell apoptosis and inhibit cell activity. The increase of ING4 can promote the downstream NF- $\kappa \mathrm{B}$ and FoxO3 apoptosis pathways $(11,12)$, so the increase of ING4 is the direct cause of the increase of cell apoptosis rate. In this study, the downregulation of caspase-3, Bax and $\beta$-catenin expression and the increase of apoptosis rate in colon cancer cells after knockout of ING4 also prove that ING4 can induce apoptosis.

GLI1 is a promoter of colon cancer $(18,19)$. The results showed that the loss of GLI1 leads to increased apoptosis, decreased cell activity, and upregulated expression of caspase-3, Bax and $\beta$-catenin. The above results indicated that GLI1 inhibits cell apoptosis to promote colon cancer. It is worth mentioning that bevacizumab also caused GLI1 downregulation after treating colon cancer model rats. ING4 upregulation caused by bevacizumab may be the reason for GLI1 downregulation. In colon cancer, PI3K/Akt/NF- $\kappa \mathrm{B}$ pathway can be used as upstream factor to activate GLI1, while PI3K/Akt/NF- $\kappa$ B pathway is negatively regulated by PTEN $(18,21)$. Previous studies have shown that ING4 is co-expressed with PTEN (22-24). In addition, ING5, a homologous protein of ING4, inhibits Akt activity (25). In this study, after bevacizumab treatment of colon cancer model rats, PTEN expression is upregulated, while $\mathrm{PI} 3 \mathrm{~K}, \mathrm{Akt}, \mathrm{NF}-\mathrm{\kappa B}$ expression is downregulated. Based on the 
results of this study and previous studies, it is speculated that the upregulation of ING4 caused by bevacizumab can promote PTEN expression, while PTEN and ING4 will jointly inhibit the activity of PI3K/Akt/NF- $\kappa \mathrm{B}$ pathway. Finally, this series of cascade reactions lead to the decrease of GLI1 expression with the decrease of upstream pathway activity.

The results also suggested that GLI1 can reduce the sensitivity of colon cancer cells with bevacizumab, while ING4 can improve the sensitivity of colon cancer cells with bevacizumab, which indicates that regulating GLI1 and ING4 expression in clinical application is helpful to improve the efficacy of bevacizumab.

The results of this study showed that bevacizumab inhibit colon cancer cells by regulating the expression of GLI1 and ING4, and found that the dosage of bevacizumab affected its therapeutic effect on colon cancer. In the future experimental design, the expression of GLI1 and ING4 can be used as the standard to further discuss the effects of different doses of bevacizumab on colon cancer model rats, and to select the better dose. In addition, it is also possible to find upstream and downstream factors that change by regulating the expression of GLI1 and ING4 in colon cancer, thus supplementing the mechanism network of colon cancer.

In conclusion, GLI1 downregulation and ING4 upregulation were found in the treatment of colon cancer model rats with bevacizumab, and it is believed that the upregulation of ING4 caused by bevacizumab can inhibit GLI1 expression through $\mathrm{PTEN} / \mathrm{PI} 3 \mathrm{~K} / \mathrm{Akt} / \mathrm{NF}-\kappa \mathrm{B}$ pathway. In addition, GLI1 can reduce the sensitivity of colon cancer to bevacizumab, while ING4 can enhance the sensitivity of colon cancer to bevacizumab. Therefore, in clinical treatment, targeted regulation of the expression levels of GLI1 and ING4 will help to improve the effectiveness of bevacizumab in the treatment of colon cancer.

\section{Acknowledgements}

Not applicable.

\section{Funding}

No funding was received.

\section{Availability of data and materials}

The datasets used and/or analyzed during the present study are available from the corresponding author on reasonable request.

\section{Authors' contributions}

BS wrote the manuscript, interpreted and analyzed the data. CW performed flow cytometer, MTT assay and Western blotting. FM contributed to observation indexes analysis. The final version was read and adopted by all the authors. All authors read and approved the final manuscript.

\section{Ethics approval and consent to participate}

The study was approved by the Ethics Committee of General Hospital of Heilongjiang Province Land Reclamation Bureau (Harbin, China).

\section{Patient consent for publication}

Not applicable.

\section{Competing interests}

The authors declare that they have no competing interests.

\section{References}

1. Vasaikar S, Huang C, Wang X, Petyuk VA, Savage SR, Wen B, Dou Y, Zhang Y, Shi Z, Arshad OA, et al; Clinical proteomic tumor analysis consortium: Proteogenomic analysis of human colon cancer reveals new therapeutic opportunities. Cell 177: 1035-1049.e19, 2019.

2. Zhang L, Cao F, Zhang G, Shi L, Chen S, Zhang Z, Zhi W and Ma T: Trends in and predictions of colorectal cancer incidence and mortality in China from 1990 to 2025. Front Oncol 9: 98, 2019.

3. Laish I, Mizrahi J, Naftali T and Konikoff FM: Diabetes mellitus and age are risk factors of Interval colon cancer: A case-control Study. Dig Dis 37: 291-296, 2019.

4. Haggar FA and Boushey RP: Colorectal cancer epidemiology: Incidence, mortality, survival, and risk factors. Clin Colon Rectal Surg 22: 191-197, 2009

5. Zhu RT, Gutkind JS, Johnson DE and Grandis JR: PIK3CA mutations in colorectal and breast cancer: Impact on oncogenesis and response to nonsteroidal anti-inflammatory drugs. In: Targeting Cell Survival Pathways to Enhance Response to Chemotherapy. Johnson DE (ed). Academic Press, Cambridge, MA, pp123-144, 2019.

6. Oh M, McBride A, Yun S, Bhattacharjee S, Slack M, Martin JR Jeter J and Abraham I: BRCA1 and BRCA2 gene mutations and colorectal cancer risk: Systematic review and meta-analysis. J Natl Cancer Inst 110: 1178-1189, 2018.

7. Sabry D, El-Deek SEM, Maher M, El-Baz MAH, El-Bader HM, Amer E, Hassan EA, Fathy W and El-Deek HEM: Role of miRNA-210, miRNA-21 and miRNA-126 as diagnostic biomarkers in colorectal carcinoma: Impact of HIF-1 $\alpha$-VEGF signaling pathway. Mol Cell Biochem 454: 177-189, 2019.

8. Wen YA, Xiong X, Scott T, Li AT, Wang C, Weiss HL, Tan L, Bradford E, Fan TWM, Chandel NS, et al: The mitochondrial retrograde signaling regulates Wnt signaling to promote tumorigenesis in colon cancer. Cell Death Differ 26: 1955-1969, 2019.

9. Ostermann AL, Wunderlich CM, Schneiders L, Vogt MC, Woeste MA, Belgardt BF, Niessen CM, Martiny B, Schauss AC, Frommolt $\mathrm{P}$, et al: Intestinal insulin/IGF1 signalling through FoxO1 regulates epithelial integrity and susceptibility to colon cancer. Nat Metab 1: 371-389, 2019.

10. Du Y, Cheng Y and Su G: The essential role of tumor suppressor gene ING4 in various human cancers and non-neoplastic disorders. Biosci Rep 39: 39, 2019.

11. Ma Y, Cheng X, Wang F, Pan J, Liu J, Chen H, Wang Y and Cai L: ING4 inhibits proliferation and induces apoptosis in human melanoma A375 cells via the Fas/caspase- 8 apoptosis pathway. Dermatology 232: 265-272, 2016.

12. Qian F, Hu Q, Tian Y, Wu J, Li D, Tao M, Qin L, Shen B and Xie Y: ING4 suppresses hepatocellular carcinoma via a $\mathrm{NF}-\kappa \mathrm{B} / \mathrm{miR}-155 / \mathrm{FOXO} 3 \mathrm{a}$ signaling axis. Int J Biol Sci 15: 369-385, 2019.

13. Cao L, Chen S, Zhang C, Chen C, Lu N, Jiang Y, Cai Y, Yin Y and $\mathrm{Xu}$ J: ING4 enhances paclitaxel's effect on colorectal cancer growth in vitro and in vivo. Int J Clin Exp Pathol 8: 2919-2927, 2015.

14. Chen Y, Huang Y, Hou P, Zhang Z, Zhang Y, Wang W, Sun G, $\mathrm{Xu} \mathrm{L}$, Zhou J, Bai J, et al: ING4 suppresses tumor angiogenesis and functions as a prognostic marker in human colorectal cancer. Oncotarget 7: 79017-79031, 2016.

15. Qu H, Yin H, Yan S, Tao M, Xie Y and Chen W: Inhibitor of growth 4 suppresses colorectal cancer growth and invasion by inducing G1 arrest, inhibiting tumor angiogenesis and reversing epithelial-mesenchymal transition. Oncol Rep 35: 2927-2935, 2016.

16. Riaz SK, Ke Y, Wang F, Kayani MA and Malik MFA: Influence of SHH/GLI1 axis on EMT mediated migration and invasion of breast cancer cells. Sci Rep 9: 6620, 2019. 
17. Yoon JW, Lamm M, Iannaccone P and Walterhouse D: GLI1 contributes to proliferation, survival and drug-resistance of Ewing sarcoma (EWS) cell. AACR: 3661, 2019.

18. Yang Z, Zhang C, Qi W, Cui Y and Xuan Y: GLI1 promotes cancer stemness through intracellular signaling pathway $\mathrm{PI} 3 \mathrm{~K} / \mathrm{Akt} / \mathrm{NF} \kappa \mathrm{B}$ in colorectal adenocarcinoma. Exp Cell Res 373: 145-154, 2018.

19. Wang X, Yao Y and Zhu X: The influence of aberrant expression of GLI1/p-S6K on colorectal cancer. Biochem Biophys Res Commun 503: 3198-3204, 2018.

20. Mulder K, Scarfe A, Chua N and Spratlin J: The role of bevacizumab in colorectal cancer: Understanding its benefits and limitations. Expert Opin Biol Ther 11: 405-413, 2011.

21. Georgescu MM: PTEN tumor suppressor network in PI3K-Akt pathway control. Genes Cancer 1: 1170-1177, 2010.

22. Watson M, Berger P, Frank S, Winn M and Miranti C: CREB1 and ATF1 differentially regulate terminal prostate luminal differentiation by controlling the timing of ING4 expression, while CREB1 prevents ING4 expression upon PTEN loss in prostate cancer. Cancer Res 78 (16 Suppl): Abstract B031, 2018.
23. Rakshit N, Yang S, Zhou W, Xu Y, Deng C, Yang J, Yu H and Wei W: Adenovirus-mediated co-expression of ING4 and PTEN cooperatively enhances their antitumor activity in human hepatocellular carcinoma cells. Acta Biochim Biophys Sin (Shanghai) 48: 704-713, 2016.

24. Wang Y, Yang J, Sheng W, Xie Y and Liu J: Adenovirus-mediated ING4/PTEN double tumor suppressor gene co-transfer modified by RGD enhances antitumor activity in human nasopharyngeal carcinoma cells. Int J Oncol 46: 1295-1303, 2015.

25. Barlak N, Capik O, Sanli F, Kilic A, Aytatli A, Yazici A, Ortucu S, Ittmann $\mathrm{M}$ and Karatas OF: ING5 inhibits cancer aggressiveness by inhibiting Akt and activating p53 in prostate cancer. Cell Biol Int cbin.11227, 2019

This work is licensed under a Creative Commons Attribution-NonCommercial-NoDerivatives 4.0 International (CC BY-NC-ND 4.0) License. 